\title{
COMPRESSÃO DO ESPAÇO-TEMPO E HIPERLOCALIZAÇÃO: OS NOVOS FLÂNEURS
}

\author{
Ivone Neiva Santos \& José Azevedo
}

\begin{abstract}
Resumo
A experiência de sensações tais como a de aceleração do tempo ou de eliminação do espaço vulgarizou-se na vida moderna cada vez mais organizada segundo o ritmo do "tempo real", instituído pelos média digitais. Neste artigo, partindo do conceito de compressão espaço-tempo de Harvey (1999), confrontamos perspetivas situadas nas correntes do determinismo tecnológico com outras que defendem a relação dialógica entre tecnologia e sociedade. Abordam-se noções como as de desterritorialização e destemporalização que permitem compreender o surgimento de um espaço de dados fragmentado e intemporal, correspondendo a uma "nova geografia", na qual já não é possível estabelecer uma fronteira clara entre o mundo físico e o digital. O texto estrutura-se tendo como suporte teórico o conceito de flâneur ciberespacial, explorando as semelhanças com o flâneur novecentista, tal como descrito por Baudelaire. A análise de um conjunto de intervenções artísticas e experimentais centradas sobre questões como a hiperlocalização ou a ubiquidade e a pervasividade permite-nos recorrer a esta figura do flâneur ciberespacial num duplo sentido, como sinal da tendência para a aceleração técnica, mas também como símbolo da força de resistência a essa mesma aceleração. Conclui-se que a evolução exponencial e a crescente "naturalização" da tecnologia nos obrigam a considerar o seu papel determinante nas dinâmicas sociais, designadamente, a partir da transformação da nossa relação com as dimensões do espaço e do tempo.
\end{abstract}

\section{SPACE-TIME COMPRESSION AND HYPERLOCALISATION: THE NEW FLÂNEURS}

\begin{abstract}
The experience of sensations such as time acceleration and space elimination has become common in modern life, which is increasingly organised in tune with the "real time" imposed by digital media. Throughout this article and starting with the concept of "time compression" presented by David Harvey (1999), the authors contrast technological determinism with other perspectives that suggest there is a dialogue-based relationship between technology and society. The text discusses notions such as deterritorialisation and detemporalisation that make it possible to understand the emergence of a fragmented and timeless data space, which corresponds to a "new geography", in which it is no longer possible to establish a clear boundary between the physical and the digital world. The text is theoretically underpinned by the concept of the $c y$ berflâneur, exploring the similarities with the $19^{\text {th }}$ century flâneur described by Baudelaire (1996). Analysis of a set of artistic and experimental interventions addressing issues such as hyperlocalisation or ubiquity and pervasiveness enables us to use the character of the cyberflâneur in a twofold sense - as a sign of technical acceleration and also as a symbol of resistance to such acceleration. The authors conclude that the exponential evolution and increasing "naturalisation" of technology obligates us to consider its determining role in social dynamics, namely by transforming our relationship with the dimensions of space and time.
\end{abstract}




\section{INTRODUÇÃO}

Este artigo procura observar o papel crítico dos média digitais em desafiar conceitos historicamente significativos de tempo e espaço, mudando a forma como as pessoas moldam suas identidades e ampliando o âmbito da mobilidade física e psicológica no mundo globalizado de hoje. Embrenhando-se crescentemente na nossa existência, através das redes sem fios ou dos sistemas de vigilância, a ubiquidade dos média digitais vem aumentando massivamente, tornando cada vez mais difícil analisarmos separadamente o que é social, tecnológico ou espaço-temporal. Partindo deste cenário, questiona-se se os conceitos de desterritorialização e destemporalização permitem compreender os usos do espaço e tempo no novo contexto caracterizado pela aceleração e fragmentação, mas também pelo surgimento de um novo espaço de dados intemporal, contínuo e pervasivo.

A invocação da figura do flâneur, explorada por Baudelaire (1996) e Benjamin (2000), no contexto da modernização e do desenvolvimento das cidades associados à industrialização, e retomada por autores como André Lemos (2009) ou Kathryn Kramer e John R. Short (2011), a propósito da evolução tecnológica e da globalização, enquadrou-se nessa estratégia de problematização, na qual identificámos aspetos deste novo contexto que associamos a uma certa flânerie ciberespacial. Isto na medida em que é um contexto que favorece a definição de itinerários pessoais e a manutenção de relações fluidas com os diferentes contextos espaçotemporais percorridos pelo cidadão/cibernauta. Igualmente, porque dá origem a movimentos de resistência à "modernidade", agora encarnada na monitorização e controlo permitidos pelo próprio desenvolvimento tecnológico associado à globalização.

Este artigo está organizado da seguinte forma: em primeiro lugar é apresentada a corrente de pensamento que estabelece uma relação determinante entre a evolução tecnológica e a forma como vivenciamos e percebemos o espaço e o tempo, relacionando esta corrente com o conceito de compressão espaço-tempo; de seguida, são enunciadas as abordagens que atribuem à tecnologia um papel instrumental, encontrando sobretudo nas dinâmicas sociais a razão de ser do que seria a crescente aceleração do tempo e eliminação do espaço características da modernidade; é ainda abordado o papel específico dos média digitais nesta transformação e, por último, é analisada a adequação da figura do flâneur à problematização da nova realidade espaçotemporal resultante da evolução da tecnologia digital e as configurações possíveis desse exercício de flânerie. Em conclusão, é apresentada uma síntese das principais ideias discutidas ao longo do artigo.

\section{COMPRESSÃO DO ESPAÇO-TEMPO E EVOLUÇÃo TECNOLÓGICA}

A relação entre a evolução tecnológica e a nossa perceção e vivência do espaço-tempo tem sido objeto de leituras bastante contrastantes. Harold Innis (1950) é um 
nome particularmente relevante na corrente que identifica uma tendência unívoca para a aceleração associada ao desenvolvimento tecnológico. A partir dos seus estudos de economia política, o autor identificou o papel determinante dos meios de transporte na evolução histórica, com implicações profundas na forma com as sociedades se estruturam e organizam (Subtil, 2014). Para Innis, as tecnologias são meios através dos quais as civilizações se expandem e estabelecem relações. $O$ autor defende que cada período histórico é caracterizado por um tipo de média dominante e, consequentemente, essa dominância produz um "viés" ou orientação para o tempo ou para o espaço (Subtil, 2014). Nas sociedades orientadas para o tempo predominariam média pesados, difíceis de transportar, mas também de destruir e, por isso mesmo, temporalmente duráveis. As tradições orais e as pinturas rupestres são exemplos dessa orientação. São meios adaptados à limitada capacidade humana de memorização, permitindo preservar o conhecimento ao longo do tempo. Por seu turno, as sociedades que Innis identifica como tendo "viés para o espaço" são orientadas fundamentalmente para o futuro, preferem média leves e perecíveis e com grande capacidade de armazenamento de informação (como os jornais ou a televisão). As sociedades modernas ocidentais, seriam, assim, moldadas principalmente por desvios espaciais e estariam orientadas para a comunicação à distância. Paul Virilio (2000), Anthony Giddens (2002) e Manuel Castells (2010) também destacam o papel das tecnologias de transporte e de comunicação, como indutoras de velocidade, física e informacional, na alteração da nossa perceção do tempo e do espaço. Marshall McLuhan (1969), de quem Innis foi professor e que o influenciou profundamente, revê-se nesta perspetiva, defendendo que cada novo média introduz uma mudança de escala, ritmo ou padrão na atividade humana.

Para Virilio (2000), as grandes revoluções históricas são, sobretudo, revoluções da velocidade. Ao permitir maior velocidade, cada novo veículo cria igualmente novas formas de comunicação e de circulação, correspondendo cada uma delas a uma revolução "dromocrática"'. Virilio defende que a faceta mais importante da revolução industrial, proporcionada pelo surgimento da máquina a vapor, consistiu na revolução dos transportes a que chama revolução do espaço-tempo. Virilio nomeia ainda outra revolução transformadora no século XIX: o surgimento da "estética do desaparecimento" (fotografia e cinema) que sucede à "estética do aparecimento" (a pintura e a escultura). Na sua perspetiva, a velocidade de captação da imagem na fotografia instantânea e a velocidade de projeção de imagens no filme (24 por segundo), fundados na persistência retiniana, permitiram passar "da persistência de um substrato material - o mármore ou a tela do pintor - à persistência cognitiva da visão" (Virilio, 2000, p. 24). Por isso, o cinema mostra-se "capaz de fornecer aos espectadores, em cada fração de segundo, essa sensação desconhecida de ubiquidade, numa quarta dimensão, suprimindo o espaço e o tempo" (Virilio, 1989, p. 61). De acordo com Virilio, o cinema seria posteriormente "substituído" pelo automóvel, pela viagem, correspondendo à ideia do autor de que toda a nossa vida passa por "próteses de viagens aceleradas das quais nem somos conscientes" (Virilio, 1989, p. 68), como o comboio, o automóvel, a televisão ou o computador. Para Virilio, a

\footnotetext{
' Do grego dromos, significando "pista de corridas".
} 
velocidade ganhou raízes nas vidas dos indivíduos e das sociedades, modificando continuamente valores e perceções. O autor defende ser a partir de Albert Einstein e da sua conceção relativista do mundo que se institui uma nova conceção da realidade, na qual a velocidade se sobrepõe ao tempo e ao espaço, da mesma forma que a luz supera a matéria (Virilio, 1989). Ao atingirmos a velocidade-limite, teríamos substituído o tempo histórico, domínio da História, e o espaço físico, domínio da Geografia, pelo presente único, sem dimensão humana, o que, de acordo com Virilio, nos remete paradoxalmente para o "grande encarceramento" identificado por Michel Foucault (1978). Nesta perspetiva, estaríamos encerrados, não numa prisão, mas "na rapidez e na inanidade de qualquer deslocação" (Virilio, 2000, p. 61). Virilio preocupa-se, devido a esse motivo, com a ubiquidade e a instantaneidade proporcionadas pelos média digitais. Isto porque, embora toda a História aconteça num tempo local, a aplicação do tempo real, que é o ritmo da imediatez de resposta possibilitada pela tecnologia digital, não tem relação com o tempo histórico. A experiência quotidiana ficaria, assim, reduzida ao imediatismo do presente contínuo (Virilio, 2000). Esta leitura pode ser relacionada com o conceito de compressão do espaço-tempo, formulado por David Harvey (1999). Na perspetiva de Harvey, o espaço e o tempo foram "comodificados". Homogeneizados, por um lado e fragmentados, por outro, convertem-se em mercadorias transacionáveis, constituindo um sustentáculo do capitalismo e da globalização, ao contribuir para a cada vez maior irrelevância do Estado nacional em prol da economia financeira mundial (Löw, 2008). 0 conceito de Harvey pretende dar conta de um processo que altera a relação entre o espaço e o tempo, nomeadamente através da inovação tecnológica e da globalização. Segundo Harvey, a compressão está ligada ao aumento da velocidade associado ao desenvolvimento dos meios de transporte e de comunicação, porque a experiência do espaço depende, em grande parte, do tempo que é necessário para o percorrer (Rosa, 2013). Refletindo sobre a própria natureza do espaço, Harvey (2015) propõe três dimensões de análise: o espaço absoluto, o espaço relativo e o espaço relacional.

O espaço absoluto (cartesiano-newtoniano) é uma entidade fixa e independente, sem ambiguidades, e, por isso, passível de observação e classificação pelo homem. Socialmente, corresponde a entidades territoriais claramente delimitadas, como os Estados ou a propriedade privada. Para o autor, a produção de "espaços", sua organização e distribuição, é uma faceta central do capitalismo. O espaço relativo (einsteiniano) é já o da relação entre objetos, dependendo, por isso, da existência destes e, também, do ponto de vista do observador. Esta conceção de espaço é indissociável do tempo - o espaço-tempo relativo da velocidade da luz - e de fatores que interferem nessa relação (como a evolução social e tecnológica). Harvey nota, no entanto, não ser possível compreender diferentes realidades a partir da mesma moldura espaçotemporal ${ }^{2}$. Por isso, inspirando-se em Leibniz ${ }^{3}$, propõe ainda o conceito de espaço relacional, aquele que só existe na medida em que faz parte do processo que o define. Para Harvey, os "processos

${ }^{2} \mathrm{O}$ autor refere os fluxos financeiros e os fluxos de energia nos processos ecológicos como exemplos de "espaço temporalidades incompatíveis" (Harvey, 2015).

3 Por razões teológicas, Leibniz contestou a formulação de tempo absoluto de Newton, implicando que Deus estaria "dentro" do espaço, o que era incompatível com a visão de Deus como criador do espaço e do tempo (Harvey, 2015). 
não ocorrem no espaço, mas [antes] definem [o] seu próprio quadro espacial" (Harvey, 2015, p. 130). Por esse motivo, também aqui o espaço é indissociável do tempo, estando o foco colocado na relação entre ambos. Embora o espaço-tempo relacional sugira dificuldades de medição, para o autor, as três conceções são válidas, dependendo a sua aplicabilidade dos objetivos: o espaço absoluto pode adequar-se quando se trata de definir fronteiras ou propriedades, mas já não, por exemplo, para considerar as posições relativas dos sujeitos nem as experiências vividas por cada um de nós. Não menos relevante neste contexto, Harvey assinala a espacialização do pensamento, expresso no uso de metáforas espaciais na literatura e nas artes, como a distinção entre espaço real e virtual. O segundo seria habitado pelas "imagens e [as] ilusões intangíveis que constituem o coração de todas as práticas estéticas" (Langer citado em Harvey, 2015, p. 135).

Segundo Harvey, a distinção de Ernst Cassirer (citado em Harvey, 2015, p. 136) entre espaços orgânicos, percetivos e simbólicos (este último, abstrato, associado à geometria e às interpretações artísticas), terá estado na origem de uma outra classificação, proposta por Henri Lefebvre (citado em Harvey, 2015, p. 136) que conjuga os espaços experimentado (material), conceptualizado (a forma como ele é representado) e vivido (das emoções e significados). Harvey articula a sua classificação e a de Lefebvre com três conceitos-chave de Karl Marx (1887) valor de uso, valor de troca e valor. O valor de uso inscreve-se no domínio do espaço e do tempo absolutos. Já a troca implica uma relação, movimento de mercadorias, capital, pessoas, inscrevendo-se por isso no espaço tempo-relativo. De acordo com Marx (citado em Harvey, 2015), a troca alteraria constantemente as coordenadas espaço-tempo ao inscrever-se num movimento contínuo. Com o surgimento do dinheiro, o valor, o movimento de circulação torna-se ainda mais fluido, inscrevendo-se já no espaço-tempo relacional.

O controlo do tempo e do espaço possibilitado pelo dinheiro constituiria o sustentáculo do capitalismo. Harvey cria uma matriz reveladora de que o que acontece em cada uma das dimensões consideradas apenas adquire sentido em termos dialéticos, justificando, assim, a sua abordagem relacional4. Giddens também propõe uma abordagem que se inscreve nesta lógica "relacional", quando define o espaço pela sua função social e não tanto pela sua materialidade (Löw, 2008). Para Giddens, o processo a que chama "regionalização" consiste precisamente na divisão do espaço e do tempo por regiões associadas a determinadas práticas sociais. A propósito do desenvolvimento tecnológico, Giddens (2002) propõe o conceito de distanciação do espaço-tempo para se referir ao facto de os eventos sociais aparecerem desconectados da matriz espaçotemporal. Castells (2010) também descreve a perturbação sistemática na ordem sequencial das práticas sociais como a forma de tempo dominante das sociedades em rede, diluindo a experiência temporal no "ciberespaço intemporal" (Castells citado em Sora, Jordà \& Codina, 2017, p. 197). Castells (2010) refere-se à capacidade de reconfiguração constante da internet, caracterizada pela ausência de limites de tempo e espaço. Para o autor, esta reconfiguração pode assumir a forma de compressão ou introduzir descontinuidade na sequência. De acordo com Hartmut Rosa (2013), perante a velocidade e

\footnotetext{
4 Harvey apresenta o "Ground Zero" em Manhattan como exemplo dessa "tensão dialética" (2015, p. 141).
} 
capacidade de registo quase ilimitada da tecnologia digital, o tempo estaria a perder o seu carácter linear à medida que a sequência cronológica dos eventos parece dissolver-se progressivamente. Ao comprimir o tempo faz com que, no limite, o próprio tempo desapareça, tornando-se num equivalente à eternidade (Rosa, 2013).

$\mathrm{Na}$ mesma linha de pensamento, Robert Hassan e Ronald E. Purser, citados em Sora et al. (2017, p. 197) consideram a assincronia como a verdadeira temporalidade, argumentando que a Internet permite aos atores sociais envolverem-se em comunicações em diferentes espaços e tempos, independentemente do tempo real local. Assim sendo, o tempo seria, simultaneamente, homogéneo e quase infinitamente fragmentado nas múltiplas temporalidades síncronas e assíncronas que coexistem na rede. $A$ experiência da modernidade seria, assim, para estes autores, não tanto a da aceleração, mas a da simultaneidade de tempos diversos, sendo certo que sem a velocidade, ou a imediatez, proporcionadas pelo desenvolvimento tecnológico, tal simultaneidade não seria possível.

Em suma, as perspetivas apresentadas confluem para a atribuição de um papel fundamental ao desenvolvimento tecnológico na alteração da forma como o espaço e o tempo e sua relação são vivenciados e percecionados. $O$ aumento sistemático da velocidade obtida com os meios de transporte e de comunicação, até ao limite de a tecnologia digital nos facultar atualmente acesso a qualquer lugar do mundo ao ritmo do tempo real, teria como resultado o fenómeno de alteração das coordenadas de espaço e tempo e a necessidade da adoção de novas abordagens conceptuais e novas classificações que nos permitam compreender esta nova realidade espaçotemporal.

\section{COMPRESSÃO DO ESPAÇO-TEMPO E MUDANÇA SOCIAL}

Outros autores conferem à tecnologia menor "protagonismo", enquadrando-a num conjunto mais vasto de dinâmicas sociais. Rosa (2013) defende que o princípio da aceleração faz parte da própria cultura da modernidade, sendo anterior à sua concretização tecnológica. Embora se aproxime da perspetiva de Virilio, ao identificar duas ondas de aceleração na história da civilização ocidental (a primeira associada às inovações tecnológicas trazidas pela Revolução Industrial e a segunda à revolução digital e à globalização), considera que os processos de transformação permanente não podem ser compreendidos deterministicamente a partir da aceleração tecnológica. Esta é antes um sintoma da aceleração da mudança social. No mesmo sentido, Sarah Sharma (2014) qualifica como simplista a abordagem daqueles a que chama "teóricos da velocidade". Para a autora, embora o discurso sobre a velocidade se tenha tornado hegemónico, não reflete a complexidade e os diferentes ritmos que compõem a vivência social. Sharma contesta que a velocidade deva ser entendida como uma tendência homogénea associada a uma determinada época ou tecnologia dominante. Vê-a antes como um mecanismo de diferenciação social, típico do capitalismo contemporâneo global. Para exprimir a sua visão, propõe o conceito de "cronografia do poder", de acordo com o qual alguns

\footnotetext{
${ }_{5}$ A partir do conceito de "geometria do poder" de Massey (1991).
} 
grupos seriam mais responsáveis do que outros pela compressão do espaço-tempo, uma vez que fazem uso dessa compressão, transformando-a em vantagem.

A este propósito, Sharma explora os paradoxos da figura do corporate warrior, simultaneamente privilegiado, porque está na vanguarda das redes da comunicação e do capital, e vulnerável porque é vítima, por exemplo, do jet lag ou do stress ou está dependente da disponibilidade de outros cujas temporalidades são menos valorizadas (como os taxistas ou os funcionários dos hotéis, por exemplo). Em resumo, para Sharma, não é a velocidade que produz a desigualdade, mas o seu poder explicativo, normalizador, como se fosse uma experiência uniforme no momento contemporâneo que valoriza o tempo de alguns, em detrimento de outros e exclui aqueles que o experienciam de forma diferente.

Nesta linha de pensamento, a autora critica as estratégias de desaceleração "ideológica" como os movimentos slow, chamando a atenção para o facto de a capacidade de abrandar constituir, ela própria, uma forma de privilégio que, por outro lado, pressupõe um posicionamento individualista e despolitizado. Como alternativa, a autora propõe a criação de "tempos públicos", conceito pensado para complementar a noção de "espaço público" e chamando assim atenção para o carácter desigual destas esferas "públicas". No mesmo sentido, Lemos (2009) considera que se a mobilidade nas sociedades atuais é "ampliada", não é neutra. A mobilidade física, com os mais avançados meios de transporte, e a mobilidade informacional, com a internet sem fios e os dispositivos portáteis, variam correlativamente em função da posição ocupada pelos indivíduos e grupos nas estruturas de poder. Assim sendo, os que mais facilmente se podem movimentar pelo ciberespaço são também aqueles que têm mais autonomia para a mobilidade física.

Doreen Massey (1991) questionara até que ponto a relativa mobilidade de uns e o seu poder sobre a mobilidade e a comunicação de outros aumenta o aprisionamento espacial destes últimos. Propôs o conceito de "geometria do poder", dando conta de que diferentes grupos sociais se posicionam em locais muito diferentes na corrente dos fluxos e interações associados à globalização, tendo uns a liberdade de se mover e outros permanecendo "aprisionados" no mesmo sítio e sendo, por isso, tendencialmente mais defensivos em relação a este ${ }^{6}$. Este novo contexto torna também menos claro o que queremos dizer quando falamos de "lugares" e mais complexa a forma como nos relacionamos com eles. Massey defende que a especificidade de um "lugar" é construída a partir de uma constelação de relações sociais e é portadora de múltiplas identidades. Rejeita, por isso, a identificação do lugar com uma determinada comunidade. Esta pode existir em diferentes localizações em simultâneo e é, ela própria, heterogénea, já que as pessoas ocupam posições diferentes no seu interior.

A ideia de espaços habitados por comunidades homogéneas que persiste no imaginário social é contrariada pela tendência atual para a fragmentação e rutura espacial. Não obstante, Massey também critica a ideia de que a busca de um sentido do lugar seja necessariamente reacionária. O sentido de enraizamento pode ser uma fonte de identidade positiva se se definir não por oposição ao exterior, mas na sua relação com ele,

${ }^{6}$ Esse seria, de acordo com Harvey (citado em Antonsich, 2011), o paradoxo da globalização que, fazendo os lugares parecerem menos estáveis e seguros, tornaria as pessoas mais ligadas a eles. 
afastando a perceção de vulnerabilidade do local face ao global. Massey procura, assim, "pacificar" a relação entre o local e o global, defendendo o que chama "sentido progressivo do lugar", concebendo-o como uma construção heterogénea, dinâmica, sem fronteiras e atravessada por redes que extravasam a escala geográfica.

A "desterritorialização" da organização social é uma tese partilhada por um crescente número de autores. Ash Amin (2002) questiona mesmo até que ponto continua a fazer sentido a separação entre lugar (entendido como próximo e íntimo) e espaço (percebido como longínquo e intrusivo) quando a conceção escalar do território é alterada pela globalização. A mobilidade e a interatividade proporcionadas pelo novo contexto comunicacional interferem com as formas de organização social territoriais, criando novas relações entre espaço e lugar. Segundo Amin, as novas espacialidades propostas pela globalização devem ser lidas como redes que estão além de qualquer escala geográfica (2002).

Não se trata de uma alteração nas relações de poder entre escalas espaciais, mas antes de uma "desterritorialização" ou "reterritorialização" da organização social. Trata-se de reconhecer a influência de práticas e configurações não territoriais nas próprias políticas espaciais. Como referem Paul Dourish e Genevieve Bell (2007), as infraestruturas e a computação pervasiva têm a capacidade de reconfigurar a relação entre o local e o global. Nesta perspetiva, a cidade já não seria o sítio das políticas de lugar, mas, antes, de políticas plurais e de múltiplas espacialidades.

\section{(DES)CoMPRESSÃo do ESPAÇO-TEMPO E TECNOLOGIA DIGITAL}

A proposta de Amin parece corresponder ao cenário resultante da evolução dos média digitais que impregnam crescentemente todas as dimensões da vida quotidiana. Gere (2008) assinala de facto que a distribuição de conteúdos de banda larga e as redes sem fios têm aumentando massivamente a forma como a tecnologia digital se embrenha na existência. Esta omnipresença, a que Mark Weiser chamou "ubiquitous computing" (citado em Dourish \& Bell, 2007), traduz-se na existência de interação com o computador em qualquer lugar. O crescimento dos sistemas de vigilância e a "internet das coisas", com dispositivos que podem comunicar entre si e coordenar-se, são expressões dessa expansão (2007, p. 1).

Se, por um lado, os média são descritos como fontes de suspensão e instantaneidade devido à aceleração que potenciam, por outro, são também produtores de tempo e espaço, material e simbólico (Parmett, 2017). A este propósito, e invocando o" fim da geografia", Stephen Graham (1998) tal como Harvey, chamara a atenção para o uso de metáforas geográficas como ciberespaço ou sítio, apontando os efeitos do seu uso (por referência a algo que não é mais do que uma rede de sinais eletrónicos) na concretização de novos sistemas que se tornam visualizáveis e "territoriais". Estas metáforas seriam, então, constructos ideológicos, contendo também ideias normativas sobre como a tecnologia se deve relacionar com a sociedade`. Estudando esta relação, Graham

7 O uso de conceitos como "sociedade da informação" ou "era da informação" para representar a própria natureza da sociedade atual são outros exemplos (Graham, 1998). 
identificou três tendências principais: a "substituição e transcendência", a "coevolução" e a "recombinação".

A primeira tendência ("substituição e transcendência") enquadra-se no determinismo tecnológico, que comporta, segundo o autor, duas visões do futuro. Uma em que as relações baseadas na proximidade serão substituídas pelas redes digitais, libertando a sociedade capitalista dos seus constrangimentos espaciais e temporais. E outra na qual o desenvolvimento de ambientes virtuais imersivos que "permitem que as qualidades imersivas do lugar geográfico sejam transmitidas remotamente" (Graham, 1998, p. 168), torna possível viver à distância e instantaneamente interações até aqui só acessíveis no local físico.

A este propósito, Amin recorre a uma expressão de Jan Aart Scholte "mundo sem fronteiras" (Amin, 2002, p. 386), como Castells falara em "ciberespaço intemporal". Esta perspetiva pode ser entendida como utópica ou distópica. Se Paul Virilio (2000), como vimos, tem uma visão crítica, afirmando que ao atingir-se a velocidade da luz, o espaço e o tempo são substituído pelo presente único, que "aprisiona", ao tornar inútil qualquer deslocação, cyber-gurus como Bill Gates e Nicholas Negroponte acolhem com agrado a ideia de que ambientes 3D proporcionados pela conjugação da realidade virtual e da banda larga possam, pela sua verosimilhança, substituir e tornar desnecessária a deslocação aos lugares reais. Estaríamos a falar de um território alternativo sem as limitações dos espaços físicos, utopia tecnológica intimamente relacionada com a ideologia do progresso, típica das sociedades capitalistas modernas (Graham, 1998).

A segunda tendência ("coevolução") defende que o espaço virtual não substitui o real, antes o integra e evolui em articulação com este. A tecnologia é perspetivada no quadro mais vasto da luta, sempre assimétrica, pelo poder, nomeadamente no que se refere ao controlo do espaço e da distância. Nesta ótica, a tecnologia penetra a organização espacial "real", tornando-a mais rápida e eficaz, mas as metrópoles permanecem e mantêm o seu domínio, integrando-a, e as novas possibilidades que oferece, nas suas práticas. Por um lado, os lugares são progressivamente incorporados numa rede poderosa de transações. Por outro, esse poder depende de infraestruturas de comunicação e transporte interligadas territorialmente (Harvey citado em Parmett, 2017).

Staple (citado em Graham, 1998, p. 175) assinala ainda o surgimento de um "novo tribalismo" possibilitado pelas redes digitais, as quais, se permitem comprimir o espaço e o tempo, também suportam uma lógica fragmentada de diferenciação. Assim, provocariam uma "explosão geográfica do espaço" (Graham, 1998, p. 174), já que, ao invés de reunir todos num único ciberespaço, pelo contrário, aprofundariam o relacionamento e o compromisso de diferentes indivíduos e grupos com lugares específicos (materiais ou virtuais). Estudos relacionados com comunidades diaspóricas ou minorias étnicas conduzidos por Kim (2016) e Heyd e Honkanen (2015) corroboram essa perspetiva.

A terceira tendência identificada por Graham, a "recombinação", está alicerçada na Teoria Actor-Rede, que identificava nos anos 90 do século passado a dificuldade cada vez maior de separar o "social", o "espacial" e o "tecnológico", defendendo que a noção de rede nos liberta da "tirania dos geógrafos" (Latour, 1996, p. 371) na definição do espaço. Esta teoria propõe uma conceptualização segundo a qual a tecnologia é simultaneamente 
constituída por elementos técnicos e por elementos e processos sociais difíceis de discernir de forma isolada (Latour, 1996). Através da tecnologia, a vida espacial seria continuamente recombinada em novas disposições de espaço e tempo, provisórias e "localizadas", não passíveis de generalização. Nesta perspetiva, as fronteiras que separam o ser humano da máquina são porosas, permeáveis e "ciborguianas" (Graham, 1998, p. 178).

O ciberespaço produz uma rede múltipla e fragmentada de infraestruturas e relações, através da qual novas configurações espaçotemporais são continuamente criadas. Por exemplo, aproxima certos lugares geograficamente distantes e afasta outros fisicamente próximos ou estabelece ligações fluidas, interativas e individualizadas com os lugares (Georgalou, 2015). Deste modo, a tecnologia, se transforma a cultura de espaços concretos, assume-se também como um lugar de produção cultural (Dourish \& Bell, 2007).

Lev Manovich (2006) analisou a forma como as pessoas vivem o espaço quando este está inundado de informação multimédia, como nos centros comerciais ou nos aeroportos. O autor propõe o conceito de "espaço aumentado" 8 para descrever o espaço sobrecarregado de informação, habitualmente em formato multimédia. Assinala que a omnipresença do ciberespaço se tornou a norma no século XXI, tendo o espaço físico sido invadido por informação digital, desde a ubiquidade da vigilância eletrónica e do mobile aos écrans em espaços públicos ou à possibilidade de acedermos remotamente a informação variada através dos nossos telemóveis. A interligação entre estas dimensões, de acordo com Manovich, cria um "espaço de dados" contínuo que se estende e preenche todo o espaço físico ${ }^{9}$. Por isso, o espaço da era digital já não é geométrico e estável, mas aberto, mutável e de contornos variáveis. Esta tendência enquadra-se no novo paradigma descrito por Nadav Hochman e Lev Manovich (2013), no qual se assume que os média digitais deixam de atuar como plataformas para passar a agir como agregadores de dados, abertos à manipulação e reconfiguração. Trata-se de um ambiente que cada um pode explorar, já não em função de hierarquias, mas de relações e sequências, "enquanto nos movemos do singular para o plural, do próximo para o distante" (Hochman \& Manovich, 2013, p. 37), rompendo, assim, fronteiras físicas e virtuais. Esta evolução pode incorporar mudanças positivas, tais como o acesso a serviços e informação nem sempre acessíveis e no local onde elas são mais necessárias - no lugar próprio (Schroeter \& Foth, 2009), mas sugere, também, interrogações por causa do carácter organizador e disciplinador destes meios e dos seus efeitos ao nível da proteção da privacidade/liberdade dos cidadãos (Parmett, 2017).

Esta análise, na ótica dos dispositivos móveis, percebendo o utilizador como prosumer de informação, identifica caraterísticas "recombinatórias", sugerindo mesmo um novo paradigma, segundo o qual as capacidades do computador são "transferidas" para o utilizador ${ }^{\circ}$. No entanto, ao considerar a ubiquidade da sua presença, particularmente

\footnotetext{
${ }^{8}$ Criado a partir do conceito de "realidade aumentada", por oposição a "realidade virtual" que pressupõe um espaço alternativo, simulado, ao passo que a primeira existe no espaço real.

${ }^{9}$ Manovich salvaguarda que, na prática, ocorre descontinuidade, já que, por exemplo, as câmaras de vigilância não vigiam todos os espaços e os sinais de rede são mais fracos ou até inexistentes em determinadas áreas.

${ }^{10}$ Amin refere mesmo que, nesta perspectiva, o "espaço aumentado" se relacionaria com o sonho de Douglas Engelbart do computador aumentando o intelecto humano (Amin, 2002, p. 225).
} 
dos sistemas de vigilância eletrónica, questiona o equilíbrio de forças dessa relação. Esta visão de um espaço digital contínuo que tudo cobre e impregna de informação, em diferentes sentidos, torna possível a relação com a perspetiva de Amin de uma "desterritorialização" ou, mais propriamente, de "reterritorialização" da organização social. Uma nova geografia que transforma a rede de interações e significados. Um tecido invisível em constante recombinação, que congrega as realidades física e digital numa só, tornando-se cada vez mais difícil perceber as costuras entre ambas.

\section{HiPERLOCALIZAÇÃo: NOVOS FLÂNEURS OU VELHOS PRISIONEIROS?}

Independentemente do grau de sofisticação da tecnologia, a nossa experiência está sempre dependente do lugar. $\mathrm{Na}$ parte inicial do artigo, argumentou-se que os dispositivos móveis permitem redefinir os sentidos de lugar e as próprias relações sociais. $A$ mobilidade informacional ocorre no interface entre o espaço eletrónico e o espaço físico, sendo na tensão entre as fronteiras dos diferentes territórios que um determinado lugar conquista os seus traços distintivos (culturais, sociais, etc.) e adquire assim identidade (Lemos, 2009). A mobilidade física e informacional produz lugares e os média, ao permitirem criar formas de conhecimento e de experiência localizada, ajudam-nos a expandir a nossa perceção espaçotemporal, produzindo novos "sentidos de lugar".

Segundo Lemos (2009), os média digitais criam novos territórios informacionais, diferenciados socialmente e, assim, novos sentidos de lugar, estimulando uma cultura de nomadismo. De acordo com Lemos, um pouco paradoxalmente, o desenvolvimento das sociedades industriais e capitalistas procurou "dominar" a tendência humana para o nomadismo, através de leis ou instituições promotoras do sedentarismo. Mas a globalização, também ela resultante dessa mesma evolução, viria questionar essas fronteiras, ampliando as possibilidades de deslocação, quer física, quer informacional. A cibercultura propõe assim um novo nomadismo "virtual". O email e o número de telemóvel teriam sido os primeiros "endereços não territoriais" (Attali citado em Lemos, 2009, p.30). O novo nómada é aquele que "passa pelos pontos, procurando o que está entre eles e criando percursos, procurando territórios informacionais, lugares de conexão" (Lemos, 2009, p. 31).

Esta leitura remete-nos para a figura do flâneur, personagem emblemática da Paris do século XIX, que, em 1863, Baudelaire descreve não simplesmente como um vagabundo mas como um "artista", um observador de todos os meandros da vida urbana e que nela se inspira como fonte de criação (conforme Kramer \& Short, 2011). Para Baudelaire, o flâneur é "o pintor do circunstancial e de tudo o que este sugere de eterno" (1996, p. 11), procurando pequenos detalhes efémeros da vida moderna. No século XX, Walter Benjamin recorrerá à mesma figura para criticar a modernidade (Benjamin, 2000).

O flâneur em Benjamin, como em Baudelaire, passeia-se pela cidade sem propósito definido, observando a arquitetura urbana e a multidão sem se envolver com elas, concentrado apenas no prazer do olhar. Uma figura na época de Benjamin já em vias de extinção, o flâneur é um constructo que lhe permite descrever e criticar o progresso 
associado ao desenvolvimento do capitalismo. O seu desaparecimento estaria ligado ao triunfo do capitalismo, sendo por isso apresentado como um símbolo da resistência à modernidade, ao materialismo e à aceleração artificial. O flâneur é um ser errante, que se dissocia do tempo e do espaço para definir o seu próprio itinerário e relação com os lugares que percorre, desprezando os bens materiais e privilegiando o olhar e a reflexão (Birkerts, 1982). Está destinado a ser o "estrangeiro perpétuo" que reflete o mundo sem por ele ser absorvido (Simon, 2006, p. 63), observando o espetáculo do consumismo mas não se deixando imergir acriticamente (Kramer \& Short, 2011).

De acordo com Kramer e Short (2011), nos nossos dias, reencontramos esta figura associada a respostas artísticas e sociais à urbanização massiva, nas quais a flânerie surge como um ideal de exploração crítica dos ambientes urbanos. Através do passeio, da "caminhada" como forma de tomar o pulso à vitalidade da vida nas cidades, estas abordagens exploratórias conjugam pesquisa, lazer e criação artística e fundem artistas, observadores e público numa mesma comunidade de participantes. De acordo com os autores, a globalização favorece ainda uma outra forma de flânerie. Trata-se do nómada global, o "flâneur nómada" (Kramer \& Short, 2011, p. 337) que se move de cidade para cidade ao longo da rede global de comunicações e transportes. Identificam como um exemplo desse nomadismo global precisamente o circuito das bienais e feiras de arte pelas cidades globais. O flâneur contemporâneo seria, assim, mais cosmopolita. No entanto, os autores apontam que a comodificação das cidades tende a transformar o deambular aleatório do flâneur em "percursos determinados do consumidor de história, produtos, ideias e experiências" (Kramer \& Short, p. 338). Por este motivo, defendem que a experiência do flâneur baudelairiano é ainda possível, hoje, sobretudo nas cidades dos países em desenvolvimento.

Se os média digitais desempenham um papel na construção personalizada de experiências espaçotemporais em relação às quais nos podemos posicionar como observadores-participantes (Fazel, 2018), é possível, de facto, argumentar que as novas práticas favorecidas pela tecnologia digital no século XXI podem ser analisadas a partir do conceito de flânerie transposto para o contexto ciberespacial (Fazel, 2018; Lemos, 2009; Simon, 2006). O flâneur ciberespacial, como o flâneur de Baudelaire, mantém relações "soltas" com os contextos espaçotemporais para assim se manter "móvel" (Simon, 2006).

Parece ser este o caso se considerarmos uma experiência conduzida por Bansky, numa residência artística em Nova lorque"1. Nadav Hochman, Lev Manovich e Mehrdad Yazdani (2014) analisaram esta experiência, focando-se na forma como a hiperlocalização - aqui entendida como a associação entre uma dada informação e um tempo e lugar específicos, embora os autores assinalem a falta de consenso nesta definição - através dos média sociais, influencia a perceção de eventos localizados. A partir da observação de 28.419 fotografias etiquetadas e partilhadas no Instagram, foram identificadas três

\footnotetext{
"Residência "better out than in", com a duração de um mês, realizada em outubro de 2013 , e na qual o grafiter realizava quase diariamente um trabalho num local diferente da cidade, colocando uma foto do mesmo no Instagram e pedindo aos seus seguidores que a localizassem e fotografassem. O resultado, segundo os autores, foi uma série de eventos reais e virtuais dispersos, observando-se entre si (Hochman \& Manovich, 2013, p. 4).
} 
características dos média sociais hiperlocais: a fragmentação, a temporalidade e o nomadismo. Fragmentação na medida em que a hiperlocalização converte um local num interminável número de olhares que não dão origem a um sentido único do lugar, mas a vários sentidos pessoais. Os autores consideram que a experiência hiperlocal através dos média sociais não é espacial (pois percorrendo as suas representações, não visitamos os lugares propriamente ditos). Mas é, em certa medida, temporal, quando focada na "distância" entre diferentes representações de um mesmo lugar. É temporal também porque as vivências hiperlocais são experimentadas temporalmente, não constituindo um mapa, mas um itinerário que se configura no tempo. Esta perspectiva está em sintonia com a de Harvey (1999), Giddens (2002) ou Castells (2010), que, como vimos, identificam alterações na relação espaço-tempo neste mesmo sentido, fruto da evolução tecnológica. Permitindo contruir, mais do que mapas, itinerários, as representações hiperlocais podem considerar-se nómadas, na medida em que a narrativa do lugar é realizada ao longo de diferentes percursos. Hochman, Manovich and Yazdani (2014) partiram do pressuposto de que as imagens etiquetadas, geográfica e temporalmente, e partilhadas através dos média sociais, correspondem ao espírito da vanguarda artística do final dos anos 6o, que proclamou a obra de arte site-specific, na qual cada objeto artístico apenas existe num determinado contexto espaçotemporal. Este movimento artístico surgiu em oposição ao Modernismo, que percebia as obras de arte como sendo independentes do contexto, mantendo as suas características independentemente da sua localização.

Hochman, Manovich e Yazdani (2014) classificam a primeira tendência artística como "nativa" e a segunda como "nómada". Mas a forma como a informação é partilhada na Internet assume as duas tendências opostas: tanto é anotada e classificada temporal e geograficamente, como é organizada sem qualquer relação com a sua origem (como no Google Image Search). Os resultados levaram os autores a concluir que, na experiência específica analisada, se a opção pela imagem etiquetada e o foco no local físico corresponde às aspirações da referida vanguarda artística, o uso dos média sociais incorporaram também algum "nomadismo modernista" (Hochman, Manovich \& Yazdani, p. 9), uma vez que foram partilhados por utilizadores em diferentes contextos e não apenas na sua localização original, correspondendo assim à relação solta que, de acordo com Simon (2006), o flâneur ciberespacial manteria com os diferentes contextos espaçotemporais.

No entanto, os média digitais colocam-nos também perante questões relacionadas com poder e controlo. Com efeito, se por um lado, a maleabilidade descrita permite uma certa liberdade e "vagabundagem" característica da flânerie, por outro, a desmaterialização da cultura e o upload de toda a informação para o ciberespaço - e, nesta era da geolocalização e da "internet das coisas", também o processo contrário, o download do ciberespaço (Lemos, 2009) - parecem corresponder a mecanismos de controlo mais próximos do dispositivo panótico de Foucault (1978) do que do arquétipo romântico de Baudelaire. Mas a investigação sugere que a dimensão de crítica social inerente à figura do flâneur pode ser identificada nos movimentos de resistência ao referido controlo, através da própria tecnologia. 
É o caso do estudo desenvolvido por Mark Shepard (2009) que analisou as possíveis implicações políticas e socioculturais da ubiquidade computacional, nomeadamente em contexto urbano. A "cidade senciente", de acordo com Shepard, é aquela que é capaz de ouvir e sentir. Que é capaz de reagir ativamente ao que acontece à sua volta. Mas a informação contextual a que acede é relevante. Saber onde uma pessoa está, quando e com quem, o seu histórico de compras, padrão de mobilidade, etc., permite aos sistemas sencientes fazerem previsões precisas sobre o seu comportamento. Shepard refere-se com preocupação a projetos como, por exemplo, o MIT Serendipity que usa a tecnologia Bluetooth para identificar possíveis correspondências de interesses entre pessoas. O objetivo do projeto é aumentar a produtividade empresarial, facilitando o "encontro" de colegas com interesses comuns ou necessidades complementares, que seriam alertados mutuamente dessa correspondência, o que está necessariamente associado a alguma falta de controlo por parte dos envolvidos do acesso aos seus dados pessoais $^{12}$. Outro projeto do MIT, o Gaydar, analisou dados do Facebook para verificar se as pessoas tinham consciência de toda a informação sobre si próprias que revelavam, por exemplo, simplesmente através da sua rede de amigos. De acordo com Shepard, este estudo é ilustrativo de como a informação revelada num determinado contexto pode facilmente ser utilizada para interpretar informação num contexto diferente e não previsto. Bases de dados de consumidores e sistemas de localização são mecanismos de monitorização dos cidadãos. Trata-se de sistemas pervasivos que as organizações procuram tornar invisíveis e "mundanos" (Mann, Nolan \& Wellman, 2003, p. 2).

Por um lado, sistemas de monitorização de trânsito, de controlo "inteligente" (Shepard, 2009, p. 1), semáforos, por exemplo, são aplicações aparentemente benignas dessa monitorização. Sistemas capazes de correlacionar e antecipar o comportamento humano podem facilitar a organização do quotidiano. Mas o aperfeiçoamento destes sistemas traz para o debate a questão da ubiquidade da vigilância crescentemente digital, nomeadamente porque usos menos inofensivos podem incluir dispositivos de segurança como os implementados em Londres ou Nova lorque, na sequência de ataques terroristas, incluindo câmaras de vigilância e sistemas de reconhecimento automático de matrículas. Shepard questiona as implicações destes sistemas pervasivos de segurança, nomeadamente no caso de erros do sistema. Que garantias de privacidade e autonomia tem o cidadão neste contexto' ${ }^{13}$ ?

Perante este quadro, Shepard questiona que outras práticas artísticas poderão ser concebidas, para além do uso dos média locativos para explorar espaços urbanos de forma mais ou menos original. Que papel, pergunta o autor, poderão “artistas, arquitetos e designers desempenhar na moldagem da forma como habitaremos a cidade senciente do futuro próximo?" (2009, p. 5).

Uma resposta possível poderá ser a oferecida por Steve Mann, Jason Nolan e Barry Wellman (2003), que sugerem estratégias de sousveillance (vigilância invertida) como

\footnotetext{
${ }^{12}$ Além de, como refere o autor, o termo serendipity se referir ao processo de encontrar uma coisa quando se procura algo diferente, precisamente o oposto do que acontece no projeto descrito.

${ }^{13}$ As revelações de Edward Snowden vieram precisamente evidenciar essa falta de garantias.
} 
forma de problematizar a vigilância (surveillance) e a nossa aquiescência a ela. Isto é conseguido através de tecnologias panóticas que permitam aos indivíduos observar eles próprios aqueles que os vigiam ${ }^{14}$. Com esse objetivo, os autores propõem uma série de performances "refletoras" (nas quais os papéis de vigilante/vigiado são trocados) com o objetivo de questionar a pervasividade das câmaras de vigilância e fomentar assim uma consciencialização da "natureza desempoderadora da vigilância, a sua presença esmagadora nas sociedades ocidentais e a complacência de todos os participantes perante a sua presença" (2003, p. 347). Nesta mesma lógica de consciencialização, Shepard (2009) apresenta o Sentient city survival kit, uma experiência de design de investigação sugerindo um conjunto de artefactos de sobrevivência nessa futura cidade senciente. Inspirando-se nas práticas da arqueologia, pretende-se "reconstruir" um mundo a partir de artefactos não do passado, mas do futuro próximo e assim estimular o processo de imaginar a cidade futura e promover a discussão acerca do futuro que efetivamente desejamos.

Enquadrando-se na mesma lógica de resistência proposta por Mann et al. (2003) e posicionando-se como um convite a um certo diletantismo, GPS Serendipitor é um dos artefactos propostos no âmbito do projeto de Shepard (2009). Trata-se de um software de navegação que sugere percursos alternativos para percorrer a distância entre dois pontos, percursos esses que o utilizador não tenha realizado anteriormente. O pressuposto é o de que na cidade futura encontrarmos o caminho entre dois pontos não será o problema principal. O que poderá ser mais difícil será mantermo-nos conscientes daquilo que acontece ao longo do percurso. Parece-nos inegável que promover o escapismo nómada na futura cidade senciente e controladora, é também resistir-lhe, cultivando uma certa flânerie, nos velhos moldes da figura novecentista. Mas, pergunta Shepard, "quais as implicações de uma sociedade que precisa de descarregar uma aplicação para procurar o acaso?" (Shepard, 2009, p. 6).

Em síntese, poderíamos concluir que o flâneur digital, tal como o flâneur urbano contemporâneo, pode assumir duas configurações: uma mais individualista e experiencial, se nos cingirmos às possibilidades oferecidas pela hiperlocalização na definição de itinerários individualizados, outra mais consciente e crítica, se considerarmos as abordagens orientadas para a tomada de consciência e resistência à pervasividade dos sistemas controlo e da vigilância.

\section{Conclusão}

Neste texto, partimos do pressuposto de que a evolução dos média digitais interfere na relação que os humanos tecem com o espaço e o tempo, nomeadamente favorecendo a perceção de eliminação de um e de aceleração do outro. Partindo do conceito de compressão do espaço-tempo (Harvey, 1999), ao longo deste artigo, apresentamos

\footnotetext{
${ }^{14}$ Os autores apresentam como exemplo a filmagem realizada por um cidadão americano do momento em que agentes policiais espancaram Rodney King, o que permitiu o julgamento dos responsáveis e uma discussão pública em torno da brutalidade das forças policiais.
} 
sumariamente perspetivas que identificam um papel determinante da tecnologia nessa alteração, confrontando-as com outras que privilegiam o papel da mudança social.

Parece-nos relevante analisar a relação entre as quatro dimensões aqui consideradas - tempo, espaço, tecnologia e sociedade, nomeadamente face à inevitabilidade da permanente evolução social e tecnológica. De todo o modo, independentemente de o entendermos como causa primeira ou simples ferramenta, o papel da tecnologia digital e das possibilidades por ela oferecidas nesta transformação é incontornável. A tecnologia digital impregna crescentemente todas as dimensões da vida social, tornando, como refere Manovich (2006), o "ciberespaço" já não um mundo alternativo (utópico ou distópico) dos primórdios da informática, mas antes a própria norma, com interferência relevante ao nível da perceção e vivência do espaço-tempo. Castells utiliza mesmo o conceito de "ciberespaço intemporal" (2010), para descrever a experiência espaçotemporal nas sociedades em rede. O conceito de "reterritorialização" da organização social parece-nos refletir aquela que será uma nova geografia em constante recombinação, que congrega as realidades física e digital numa só.

Invocamos a figura do flâneur porque identificamos aspetos deste novo contexto que associamos a uma certa flânerie ciberespacial. Isto porque é um contexto que, a um primeiro nível, favorece a definição de itinerários pessoais e a manutenção de relações fluidas com os diferentes contextos espaçotemporais percorridos pelo cidadão/cibernauta. A análise de uma experiência artística de Bansky relacionada com a hiperlocalização corrobora de certo modo esta perspetiva ao identificar mecanismos de fragmentação, temporalidade e nomadismo/nativismo no uso dos espaços.

Noutra perspetiva, a própria pervasividade dos média digitais parece contrariar esta possibilidade de "errância", como a análise de Manovich (2006) dos "espaços aumentados" permite perceber. Se, por um lado, a existência de um "espaço de dados" que preenche todo o espaço físico o torna também aberto à manipulação e reconfiguração individual (Manovich, 2013), por outro, a ubiquidade dos sistemas de vigilância eletrónica parece contraditória com essa autonomia. É também essa a preocupação de Shepard (2009) e de Mann et al. (2003) quando propõem reflexões suportadas em artefactos e performances artísticas que fomentam o questionamento e a consciencialização da ubiquidade dos média digitais e do seu papel enquanto instrumentos de controlo e interferência na privacidade e autonomia individual. Desta forma, são também perspetivas e estratégias que cultivam o espírito do flâneur que resiste, afastando-se da multidão, identificando e procurando salvaguardar aquilo que se vai perdendo com o "progresso". "

\section{REFERÊNCIAS}

Amin, A. (2002). Spatialities of globalisation. Environment and Planning A, 34(3), 385-399. https://doi. org/10.1068/a3439

Antonsich, M. (2011). Grounding theories of place and globalisation. Tijdschrift Voor Economische En Sociale Geografie, $102(3)$, 331-345.

Baudelaire, C. (1996). Sobre a modernidade. São Paulo: Editora Paz e terra. 
Benjamin, W. (2000). A modernidade e os modernos. Rio de Janeiro. Tempo Brasileiro.

Birkerts, S. (2018). Walter Benjamin, Flâneur: a flanerie. The lowa Review, 13(3-4), 164-179. https://doi. org/10.17077/0021-065X.2961

Castells, M. (2010). The rise of the network society. Massachusetts: Blackwell Publishing. https://doi. org/10.2307/125209

Dourish, P. \& Bell, G. (2007). The infrastructure of experience and the experience of infrastructure: meaning and structure in everyday encounters with space. Environment and Planning B: Planning and Design, 34(3), 414-430. https://doi.org/10.1068/b32035t

Fazel, M. (2018). Live montage in mediated urban-experience: Between media and architecture. In Q. M. Troiani \& I. Zamanm (Eds.), Transdisciplinary urbanism and culture - From pedagogy to praxis (pp. 89-97). Urban Book Series. Reino Unido: Springer. https://doi.org/10.1007/978-3-319-55855-4_8

Foucault, M. (1978). Discipline and punish. The birth of the prison. Nova lorque: Pantheon Books.

Georgalou, M. (2015). Placemaking and place identity in social media. In I. Theona \& D. Charitos (Eds.), Hybrid city 2015- Data to the people - Proceedings of the 3rd International Biennal Conference (pp. 361-370). Atenas: University Research Institute of Applied Communication. https://doi. org/10.1145/2505494.2505505

Gere, C. (2008). Digital culture. Londres: Reaktion Books.

Giddens, A. (2002). Modernidade e identidade. Rio de Janeiro: Jorge Zahar Editor

Graham, S. (1998). The end of geography or the explosion of place? Conceptualizing space, place and information technology. Progress in Human Geography, 22(2), 165-185. https://doi. org/10.1191/030913298671334137

Harvey, D. (1989). The condition of postmodernity: an enquiry into the origins of social change. Oxford: Blackwell Publishers.

Harvey, D. (2015). O espaço como palavra-chave. Em Pauta, 35(13), 126-152.

Heyd, T. \& Honkanen, M. (2015). From Naija to Chitown: the new african diaspora and digital representations of place. Discourse, Context and Media, 9, 14-23. https://doi.org/10.1016/j.dcm.2015.06.001

Hochman, N. \& Manovich, L. (2013). Zooming into an Instagram City: reading the local through social media. First Monday, 18(7). Retirado de http://revuecaptures.org/référence-bibliographique/ zooming-instagram-city-reading-local-through-social-media

Hochman, N., Manovich, L. \& Yazdani, M. (2014). On hyper-locality: performances of place in social media. In Proceedings of 2014 International AAAI Conference on Weblogs and Social Media (ICWSM). Retirado de http://manovich.net/index.php/projects/on-hyper-locality-performances-of-place-in-social-media

Innis, H. A. (1950). Empire and communications. Toronto: Toronto University Press.

Kim, Y. (2016). Diasporic daughters and digital media: 'willing to go anywhere for a while'. Cultural Studies, 30(3), 532-547. https://doi.org/10.1080/09502386.2015.1113638

Kramer, K. \& Short, J. R. (2011). Flânerie and the globalizing city. City: analysis of urban trends, culture, theory, policy, action, 15(3-4), 322-342. https://doi.org/10.1080/13604813.2011.595100

Latour, B. (1996). Article on actor-network theory. A few clarifications plus more than a few complications. Soziale Welt, 25(3), 1-16,369-381. https://doi.org/10.2307/40878163 
Lemos, A. (2016). Cultura da mobilidade. Revista Famecos, 16(40), 28-35. https://doi. org/10.15448/1980-3729.2009.40.6314

Löw, M. (2008). O spatial turn: para uma sociologia do espaço. Revista Tempo Social, 25(2), 17-34. https://doi. org/10.1590/So103-20702013000200002

Mann, S., Nolan, J. \& Wellman, B. (2003). Sousveillance: inventing and using wearable computing devices for data collection in surveillance environments. Surveillance and Society, 1(3), 331-355. https://doi. org/10.24908/ss.vii3.3344

Manovich, L. (2006). The poetics of augmented space. Visual Communication, 5(2), 219-240. https://doi. org/10.1177/1470357206065527

Marx, K. (1887). Capital: a critique of political economy. Volume I. Retirado de https://www.marxists.org/ archive/marx/works/download/pdf/Capital-Volume-l.pdf

Massey, D. (1991, junho). A global sense of space. Marxism Today, 24-29. Retirado de http://www.unz.org/ Pub/MarxismToday-1991jun-00024

Mcluhan, M. (1969). Os meios de comunicação como extensões do homem. Nova lorque: McGraw-Hill Book Company.Retirado de https://books.google.pt/books?id=wFvBeU1jVwIC\&lpg=PAg\&ots=K2vQDYffn7\&d $\mathrm{q}=$ marshall\%2omcluhan\&lr\&hl=pt-PT\&pg=PA6\#v=onepage\&q=marshall\%2omcluhan\&f=false

Parmett, H. M. (2017). Space. In L. Ouellette \& J. Gray (Eds.), Key words for Media Studies (pp. 181-183). Nova Iorque: NYU Press.

Rosa, H. (2013). Social acceleration. A new theory of modernity (new directions in critical theory) - Hartmut Rosa. Nova lorque: Columbia University Press.

Schroeter, R. \& Foth, M. (2009). Discussions in space. In OZCHI 2009: 21st Annual Conference of the Australian Computer-Human Interaction Special Interest Group (CHISIG) of the Human Factors and Ergonomics Society of Australia (HFESA), Nov 23-27, Melbourne. https://doi.org/10.1145/1738826.1738903

Sharma, S. (2014). In the meantime: temporality and cultural politics. Durham, NC: Duke University Press. https://doi.org/10.1215/9780822378334

Shepard, M. (2009). Sentient city survival kit: archaeology of the near future. UC Irvine: Digital Arts and Culture 2009. Retirado de https://escholarship.org/uc/item/4zpoc4x2

Simon, B. (2006). Beyond cyberspatial flâneurie: On the analytic potential of living with digital games. Games and Culture, 1(1), 62-67. https://doi.org/10.1177/1555412005281789

Sora, C., Jordà, S. \& Codina, L. (2017). Chasing real-time interaction in new media: towards a new theoretical approach and definition. Digital Creativity, 28(3), 196-205. https://doi.org/10.1080/14626268.2017.13553 23

Subtil, F. (2014). Harold A. Innis. O viés da comunicação. Comunicação Pública [Online], 8(13). Retirado de http://journals.openedition.org/cp/525

Virilio, P. (1989). Esthétique de la disparition. Paris: Éditions Galilée.

Virilio, P. (2000). Cibermundo: a política do pior. Lisboa: Editorial Teorema. 


\section{NOTAS BIOGRÁFICAS}

Ivone Neiva Santos é bolseira de investigação no projeto "CHIC Science - Cooperative Holistic view on Internet and Content". Tem experiência anterior em projetos de investigação nas áreas de comunicação de ciência e jornalismo digital. Tem também experiência relevante no sector educativo e empresarial. Frequenta o programa doutoral em Media Digitais na Universidade do Porto. É mestre e licenciada em Sociologia pela Faculdade de Letras da mesma Universidade. Entre as suas áreas de interesse, está a relação entre o desenvolvimento tecnológico, as práticas culturais e as dinâmicas sociais.

ORCID: https://orcid.org/0000-0002-5466-5572

Email: ivoneneivasantos@gmail.com

Morada: Faculdade de Letras da Universidade do Porto, Via Panorâmica, s/n , 4150564 Porto

José Azevedo, é Professor Associado da Faculdade Letras da Universidade do Porto. Foi Fulbright Scholar na Universidade do Texas, Austin (2001) e professor visitante na Universidade da Carolina do Norte - Chapel Hill (2004) apoiado pela Fundação Gulbenkian e Fundação Luso-Americana. Coordenou vários projetos internacionais, entre os quais sobre a utilização dos media digitais para o ensino das alterações climáticas. Participa na direção de várias revistas científicas e é regularmente membro de painéis de avaliação de bolsas e projetos (FCT, UT Austin Portugal entre outras).

ORCID: https://orcid.org/0000-0002-6738-1827

Email: azevedo@letras.up.pt

Morada: Faculdade de Letras da Universidade do Porto, Via Panorâmica, s/n , 4150564 Porto

* Submetido: 24/11/2018

* Aceite: 24/12/2019 